\title{
LA CUANTÍA DE LA COMPENSACIÓN ECONÓMICA
}

"Le temps d'apprendre a vivre, il est déjà trop tard..."

Aragon

\section{Carlos Pizarro Wilson*}

\begin{abstract}
RESUMEN
Este artículo consiste en un intento de elaborar pautas para el cálculo de la compensación económica. Para este cometido debe asumirse una concepción sobre la calificación de la institución, para luego, en segundo término, referirse al modelo de cuantificación a partir de las directrices indicadas por el legislador en el artículo 62 de la Ley de Matrimonio Civil. Esto permitirá establecer ciertas pautas para la fijación de la cuantía.
\end{abstract}

\section{COMPENSACIÓN ECONÓMICA - DERECHO DE FAMILIA - MATRIMONIO}

\section{The amount of the economic compensation}

\begin{abstract}
This article consists in an attempt to elaborate a guideline for the calculation of economic compensation in Family Law. To reach this end, a singular conception about the institution's legal qualification is assumed, as a basis to set a model of quantification from the guidelines indicated by the legislator in article 62 of the Civil Marriage Act. This will allow the establishment of certain principles and guidelines for the setting of the amount.
\end{abstract}

$$
\text { ECONOMIC COMPENSATION - FAMILY LAW - MARRIAGE }
$$

* Abogado, Doctor en Derecho, Profesor de derecho civil en la Universidad Diego Portales, Santiago de Chile, carlos.pizarro@udp.cl. Este artículo forma parte del Proyecto Regular Fondecyt No 1070731, del cual el autor es investigador responsable. Artículo recibido el 16 de diciembre de 2008 y aceptado para su publicación por el Comité Editorial el 18 de mayo de 2009. 
$\mathrm{E}$ n Chile, la compensación económica no ha sido el resultado de una evolución legislativa o jurisprudencial sobre la regulación de las relaciones matrimoniales una vez verificada la ruptura por nulidad o divorcio. A diferencia de otras legislaciones, no se produjo un proceso paulatino de asentamiento de la institución. ${ }^{1}$ Tampoco los daños en derecho de familia tuvieron, ni tienen un desarrollo que pueda vinculársele. ${ }^{2}$ Ausente también está, debido a la inexistencia del divorcio, una práctica de alimentos posterior a la relación matrimonial, siendo, otrora, la nulidad del acto de matrimonio basada en la incompetencia del oficial del registro civil una forma abrupta de término del vínculo. ${ }^{3}$

En el derecho comparado, al menos en aquellas legislaciones que aparecen en la discusión legislativa nacional, la compensación económica, pensión económica en una época en España y prestation compensatoire en Francia, han sufrido importantes reformas, las cuales no han sido tan espaciadas en el tiempo, lo cual muestra las dificultades en la aplicación de la institución. No existió en Chile una transición desde los alimentos entre cónyuges hacia la compensación económica. ${ }^{4}$

Esto puede significar una ventaja, en la medida que evita las confusiones con los alimentos, aunque la práctica muestra ciertos ripios derivados de entregar a la compensación económica un carácter asistencial o alimentario, como lo pretende en ciertos fallos la Corte de Apelaciones de Antofagasta, bajo el amparo de la explicación funcional del profesor Tapia Rodríguez. 5

${ }^{1}$ En el derecho francés para su evolución, véase Malaurie, Ph. y Aynés, L., La Famille, Paris, Defrénois, 2006, p. 318 y ss.; Carbonnier, J., Droit Civil. Quadrige. Manuels, Paris, Puf, vol. I, 2004, p. 1358; en España, Lalana del Castillo, C., La pensión por desequilibrio en caso de separación o divorcio, Barcelona, Bosch, 1993; Saura Alberdi, B., La pensión compensatoria; criterios delimitadores de su importe y extensión, Valencia, Tirant, 2004.

${ }^{2}$ Ver en España, AA.VV., Daños en el derecho de familia, coordinador José Ramón de Verda y Beamonte, RDP Monografías, Navarra, Thomson-Aranzadi, 2006, en particular p. 147 y ss.; Novales Alquézar, M. de A., "Hacia una teoría general de la responsabilidad civil en el derecho de familia", en Revista del Notariado, No 60, 2006, p. 197 y ss.; en Chile, Herane Vives, F., "Reparación por incumplimiento de los deberes matrimoniales", en Estudios de Derecho Civil II, Jornadas nacionales de derecho civil, Olmué, 2006, Santiago, LexisNexis, 2007, coordinadores H. Corral T. y M. S. Rodríguez Pinto, pp. 181 y ss. Para una distinción del ámbito de la compensación económica y la responsabilidad civil derivada de infracciones a deberes conyugales, ver Corte de Apelaciones de Santiago, $\mathrm{N}^{\circ}$ ingreso 7823-2006, considerando 15०: “. . han quedado acreditadas las infracciones a las obligaciones del matrimonio por parte del demandante y demandado reconvencional, los fundamentos para solicitar una compensación económica por dicha circunstancia, escapan al ámbito permitido por el artículo 61 de la Ley $19.947 \ldots$.., pudiendo solamente el tribunal, también decretar el divorcio por la causal invocada por la demandada". Y agrega "Que, en consecuencia, se desestimará la compensación económica solicitada, sin perjuicio de lo que se resuelva sobre las costas”.

${ }^{3}$ En efecto, la nulidad por mutuo consentimiento bajo el amparo de la incompetencia del oficial del registro civil ponía término a los alimentos entre cónyuges. De ahí la negociación en un número importante de casos para fijar el precio de la nulidad en el pasado.

${ }^{4}$ Para las reformas en el derecho francés, Bénabent, A., La réforme du divorce article par article, Paris, Defrénois, 2004; Massip, J., Le nouveau droit du divorce, Paris, Defrénois, 2005; AA.VV., Dossier Pratiques Francis Lefebvre. Réforme du divorce. Loi du 26 mai 2004, procédures, conséquences patrimoniales et fiscales, Levallois, Francis Lefevbre, 2004.

${ }^{5}$ Tapia Rodríguez, M., "Sobre la función y criterios de determinación de la compensación económica matrimonial”, en Semana Jurídica, enero 2007, pp. 1 y ss., quien sostiene que "La compensación económica 
Sin embargo, y en esto no puede haber controversia, la compensación económica constituye bien un crédito que nace una vez verificadas ciertas condiciones determinadas por el legislador y calificadas por el juez, aunque respecto de ellas exista, también, controversia. $^{6}$

Desde una perspectiva socioeconómica la compensación presenta varias aristas. Por una parte, las sentencias muestran una seria dificultad para establecer compensaciones con un pago único. Es decir, la extinción del crédito suele establecerse en cuotas sucesivas en el tiempo, en ciertos casos sujetas a indexación, y en escasas oportunidades amparadas con garantía como lo establece la ley. ${ }^{7}$ Es decir, en Chile, mayoritariamente la compensación se está fijando en cuotas sin garantía, prolongando la relación entre los cónyuges posdivorcio, lo cual podría originar severos problemas en épocas de crisis económicas dada la inmutabilidad del crédito devengado.

Otra circunstancia relevante es el tipo de cónyuges que ha demandado la compensación. En un número importante de casos se trata de matrimonios de larga duración, cuyo impedimento de oficializar la ruptura tuvo una salida con el divorcio por cese de convivencia con demanda unilateral. En cierta medida habrá un pago histórico, pues el cese de convivencia se produjo hace un tiempo considerable, rehaciendo la vida los cónyuges con otras familias o adaptándose a esa situación sin ninguna ayuda del otro. Este caso, el de cónyuges separados de hecho desde larga data constituye la hipótesis típica desde la entrada en vigencia de la ley. Su relevancia es difícil de ocultar, atendida las cuantías que puede alcanzar la compensación económica. Adquiere especial importancia, también, la situación de la mujer que ha logrado la manutención personal y en su época de los hijos, con la pensión de alimentos que viene a extinguirse con el divorcio. De ahí una cierta tendencia de la jurisprudencia a prolongar los alimentos ahora con un

es -como todas las instituciones vinculadas al matrimonio-funcional a las formas de relación de cada pareja y a las diversas realidades que siguen a la ruptura... pues la naturaleza de la compensación económica es directamente funcional al modelo de relación que antecedió a la ruptura, al "sendero" que siguió la pareja". Así, por vía ejemplar, Corte de Apelaciones de Antofagasta, "Barrera Molina c. Pizarro Araya”, $\mathrm{N}^{\circ}$ ingreso 1161-2005: "En la hipótesis descrita y relativa a este caso, la compensación económica jugaría una función asistencial, cercana a una pensión alimenticia reducida en el tiempo y en entidad...”. En términos textuales, citando al referido profesor Tapia, la misma Corte de Antofagasta señaló que "la compensación económica es funcional a las formas de relación de la pareja o modelo de familia y a las diversas realidades que siguen a la ruptura, que en la especie se produjo hace varios años. Conforme a ello, en este caso, la compensación económica jugará una función asistencial, cercana a una pensión alimenticia reducida en el tiempo y en entidad...”. ( $\mathrm{N}^{\circ}$ ingreso Corte 225-2006).

${ }^{6}$ Sobre la compensación económica como un derecho, Barrientos Grandón, J., "La compensación económica como "derecho" de uno de los cónyuges y "obligación” correlativa del otro. De sus caracteres, RChDP, 2007, $\mathrm{N}^{\circ}$ 9, p. 9 y ss.; acerca de la controversia para configurar la procedencia de la compensación económica, la tesis particular de Corral Talciani, H., "La compensación económica en el divorcio y la nulidad matrimonial”, en Revista Chilena de Derecho, v. 34, No 1, p. 23 y ss. Más reciente en clave comparativa, Céspedes Muñoz, C. y Vargas Aravena, D., “Acerca de la naturaleza jurídica de la compensación económica. La situación en Chile y en España”, en Revista Chilena de Derecho, vol. 35, N 3, pp. 439 y ss.

${ }^{7}$ Por vía ejemplar, Corte de Apelaciones de Rancagua, $\mathrm{N}^{\circ}$ ingreso 444-2006, se determina una compensación de 10 millones pagadera, en forma alternativa, al contado o en cuotas de 100.000 pesos mensuales. 
disfraz de compensación económica que asegure una situación análoga a la detentada hasta la dictación de la sentencia de divorcio. ${ }^{8}$

El problema que viene, entonces, dice relación con la interpretación de la institución a la luz del tipo de relaciones matrimoniales que se irán desenvolviendo en nuestra sociedad. Según muestra la experiencia comparada, debiera producirse una cierta disminución o decaimiento del matrimonio, con un aumento paulatino de las convivencias de hecho, sumado al acrecimiento de las rupturas matrimoniales luego de períodos más breves de vida conyugal. ${ }^{9}$ Pareciera existir una menor tolerancia a la vida conyugal produciéndose las crisis de pareja antes de los cinco primeros años de matrimonio. A esto se suma la inserción paulatina y consistente de la mujer al trabajo. ${ }^{10}$

Todo esto para entender que la compensación económica es una institución sensible a los cambios y transformaciones de la familia. ${ }^{11}$

Es cierto que la historia de la ley de matrimonio civil en cuanto a la compensación económica fue algo zigzagueante, con titubeos importantes, dando sombras respecto a la función, calificación y trazos de la misma. ${ }^{12}$

En seguida, una vez publicada la ley, la doctrina nacional se concentró, al menos en forma mayoritaria, en artículos tratando de explicar la compensación económica, siguiendo un método usual en los civilistas continentales, ya sea excluyendo ciertas calificaciones o asignándoles otras ya conocidas o, por último, renunciando a esa tarea. ${ }^{13}$

${ }^{8}$ En forma paradigmática, una sentencia del $1^{\mathrm{er}}$ juzgado civil de Valparaíso, rol 306-2005, en la cual se expresó: “...todo lo cual a juicio del tribunal, hace que la demanda por reconvenciones económicas, sea acogida parcialmente manteniendo sin alteración su situación patrimonial por el lapso de dos años, es decir, por tal período se mantendrá vigente la actual pensión alimenticia que recibe...”. La Corte Suprema anuló la sentencia apelada por razones de forma, al no haberse pronunciado sobre la legalidad de la sentencia de primera instancia en conformidad al trámite, ya extinto, de la consulta obligatoria.

${ }^{9}$ La tendencia se ratifica en las estadísticas del Servicio de Registro Civil, ver http://www.registrocivil.cl/f_estadisticas_enfoque_de_genero.html El número de matrimonios entre el año 2000 y el 2007 ha disminuido en una cifra cercana a los 10.000 y el año 2007 se verificaron cerca de 16.000 inscripciones de divorcios. Visitada el 11 de diciembre de 2008.

${ }^{10}$ Ver http://www.sernam.cl/cedocvi/basemujer/docs/CON(5)_20080708_170011.xls en que muestra el progresivo aumento de la inserción de la mujer al trabajo, en forma particular en el ámbito urbano. Las estadísticas van desde 1996 hasta el año 2006. Visitada el 11 de diciembre de 2008.

${ }^{11}$ Ver Tapia Rodríguez, M., "Constitucionalización del derecho de familia(s), el caso chileno: las retóricas declaraciones constitucionales frente a la lenta evolución social”, en $R C h D P, \mathrm{~N}^{\circ} 8,2007$, pp. 155 y ss.

${ }^{12}$ Una crítica argumentada en Domínguez Hidalgo, C., "Compensación económica en la nueva ley de matrimonio civil", charla efectuada el 13 de octubre de 2005, en Revista del abogado, Serie conferencias, 2005 , p. 8 y 9. Menos intenso, Vidal Olivares, A., "La compensación por menoscabo económico en la Ley de Matrimonio Civil", en Vidal Olivares, A. (coordinador), El nuevo derecho chileno del matrimonio (Ley $N^{\circ} 19.947$ de 2004), Jurídica, Santiago, 2006, p. 219.

13 Así ocurre en Barrientos Grandón, J. y Novales Alquézar, A., Nuevo Derecho Matrimonial Chileno, Santiago, LexisNexis, 2004, p. 402 y ss.; Turner Saelzer, S., "La compensación económica en la nueva ley de matrimonio civil: tres cuestiones dogmáticas", en Revista Chilena de Derecho, vol. 32, No 3, 2005, pp. 413 y ss; Pizarro Wilson, C., "La compensación económica en la nueva ley de matrimonio civil chilena", en $R C h D P$, No 3, 2004, pp. 83 y ss.; Vidal (n. 12), pp. 220 y ss.; Gómez de la Torre, M., "Compensación económica en la nueva ley de matrimonio civil" (Folleto Colegio de Abogados de Chile), Colegio de Abogados, Santiago, 2005; Veloso Valenzuela, P., “Algunas reflexiones sobre la compensación económica”, en Actualidad Jurídica, 
El primer énfasis estuvo entonces en la naturaleza jurídica de la institución. Transcurridos cuatro años de la entrada en vigencia de la ley, dicha tarea estuvo marcada por una metodología tradicional, sin tener claridad sobre la importancia de la misma, lo cual redundó en una pluralidad de razonamientos y una cierta dispersión argumentativa.

Con posterioridad, la doctrina se ha ido ocupando de problemas más específicos. Así, por ejemplo, la relación entre los artículos 61 y 62 de la LMC, y la función de los criterios entregados por el legislador. ${ }^{14}$ Como se anunció, en este trabajo se pretende avanzar sobre la cuantía de la compensación económica. Para lograrlo, reviste importancia la calificación, a fin de establecer la forma de aplicación de los criterios previstos por el artículo 62 .

La tarea de cuantificación del menoscabo económico tiene una mirada desde la calificación de la institución, a lo cual debe sumarse el análisis de la concurrencia de los criterios previstos en el artículo 62 de la LMC. En definitiva, para determinar la cuantía del menoscabo debe desplegarse un doble esfuerzo. Por una parte, definir qué debemos entender cuando hablamos de compensación económica (I) y, por otra, cómo deben operar los criterios previstos en el artículo 62 u otros que determine la jurisprudencia (II), lo que nos permitirá proponer un procedimiento de cuantificación de la misma (III).

\section{LA CUANTÍA A PARTIR DE LA CALIFICACIÓN DE LA COMPENSACIÓN ECONÓMICA}

Tal como se indicó, la calificación o naturaleza jurídica de la compensación fue la primera tarea en que se concentró la doctrina. Hoy podemos identificar tres corrientes bien definidas en relación a esta cuestión. Por una parte, encontramos aquellos que se inclinan por una calificación próxima a la indemnización, ya sea como una pérdida de la posibilidad, cercana al lucro cesante o indemnización moderada. ${ }^{15}$ Por otra, quienes

No 13, 2006, pp. 171 y ss; Tapia (n. 5), No 271; Segura Riveiro, F., "La compensación económica al cónyuge más débil”, en Revista de Derecho, Universidad de Concepción, No 214, julio-diciembre 2003, pp. 109 y ss.; en forma más atenuada por ser más recientes, Corral (n. 6), p. 24, bajo el título "De la función a la naturaleza”; Domínguez Águila, R., "La compensación económica en la nueva legislación de matrimonio civil", en Actualidad Jurídica, vol. 15, 2007, p. 91; un ejercicio comparativo clarificador en Turner Salezer, S., Las prestaciones económicas entre cónyuges divorciados en la nueva ley de matrimonio civil", en Revista de Derecho, Universidad Austral de Chile, vol. 16, 2004, pp. 83 y ss., en particular la parte dedicada a los modelos comparados de protección, para enseguida analizar el texto chileno; una excepción es el trabajo de Guerrero Becar, J. L., "La compensación económica en la ley de matrimonio civil. Análisis jurisprudencial y sobre la necesidad de revisar los supuestos de procedencia”, en Revista de Derecho, Pontificia Universidad Católica de Valparaíso, vol. XXVII, 2006, p. 4.

${ }^{14}$ Turner Saelzer, S., "Las circunstancias del artículo 62 de la nueva ley de matrimonio civil: naturaleza y función”, en Estudios de Derecho Civil, Jornadas de derecho civil, Valdivia, coordinadores Juan Andrés Varas Braun y Susan Turner Saelzer, LexisNexis, Santiago, 2005, pp. 481 y ss. La autora se ocupa de delimitar la doble función que cumplen los criterios señalados en el artículo 62 dando pautas para su implementación.

${ }^{15}$ Pizarro (13), pp. 85 y ss; Vidal, (12), pp. 219 y ss. Con todo, el profesor Vidal justifica la compensación económica como una obligación de origen legal que no coincide con ninguna otra institución, por 
identifican la compensación según el tipo de matrimonio y familia a que afecta el divorcio que podríamos denominar funcional. ${ }^{16} \mathrm{y}$, en tercer lugar, la opinión que propone un uso instrumental de la institución como freno u obstáculo al divorcio. ${ }^{17}$

Otra constatación relevante consiste en percibir las diferencias sobre qué función cumple la compensación económica. Mientras algunos plantean que ella permitirá lograr un cierto equilibrio para el cónyuge beneficiario que lo impulse o lo habilite para la necesaria reinserción una vez quebrado el proyecto familiar, dando una marcada mirada hacia el futuro una vez cumplidas las condiciones de procedencia, ${ }^{18}$ otros la entienden con un marcado acento hacia el pasado que justifica el pago de una deuda por el sacrificio que en base al proyecto de familia tuvo una causa legítima y justificada, pero que ahora con la ruptura matrimonial queda desprovisto de base ese postergamiento o desmedro que se revela como un menoscabo necesario de compensar. Todavía se sugiere ampliar dicha función, pues en opinión del profesor Corral debe admitirse la autonomía de los criterios del artículo 62 para reconocer la procedencia de la compensación. De esta manera, ésta cabría incluso sin concurrir los supuestos del artículo 61, como ocurre en el caso de la mujer postrada o discapacitada. ${ }^{19}$

Sobre la descripción de las distintas teorías acerca de la naturaleza jurídica no es necesario volver. Parece útil para avanzar en la cuantía de la compensación resolver la tensión que dichas teorías plantean sobre la mirada hacia el futuro o anclada en el pasado al momento de determinar y cuantificar la compensación económica.

\section{A. La mirada bacia el futuro}

Sobre la necesidad de observar en qué situación queda el cónyuge demandante de la prestación una vez verificado el divorcio y, asimismo, intentar su cuantificación delineando cómo será su vida futura sin el estatuto protector del matrimonio se ha pronunciado cierta doctrina colocando el énfasis en el desequilibrio. Esta noción, propia de la legislación española sobre pensión compensatoria, permite otorgar al cónyuge que queda en peor situación económica verificado el divorcio un impulso necesario

esto se aparta de la naturaleza indemnizatoria y la define desde la idea de la corrección de una disparidad o desequilibrio para enfrentar el futuro. Por su parte, Susan Turner, quien afirma la tesis indemnizatoria, sostiene que el principal elemento sería el valor del trabajo doméstico; Turner (14), aunque en forma menos intensa, pues señala que "De las características de la compensación económica anotadas se desprende que su carácter no es alimenticio sino, por el contrario, participa de la naturaleza reparatoria de la compensación compensatoria española. Sin embargo, su configuración, tanto desde un punto de vista formal como de fondo, no traduce fielmente dicha naturaleza", pp. 98 y 99.

16 Tapia (n. 5), p. 3.

${ }^{17}$ Corral (n. 6), p. 25, para quien la institución corresponde a una "indemnización por sacrificio" o “indemnizaciones por afectación lícita de derechos”. Esta conclusión la extrae a partir de la supuesta función de la compensación de constituirse en un paliativo frente al divorcio unilateral. Con todo, su propuesta también se acerca a una de naturaleza indemnizatoria.

\footnotetext{
18 Vidal (n. 12), p. 220.

${ }^{19}$ Corral (n. 6), p. 27.
} 
para su inserción social. ${ }^{20}$ En un sentido cercano, la legislación francesa busca evitar un cambio brusco en el nivel de vida del cónyuge requirente. Esta visión de la compensación económica exige al momento de cuantificarla construir el probable futuro del cónyuge demandante. Esta tesis, verificadas las condiciones de la institución y la existencia del menoscabo, otorga como función esencial al pago de la prestación evitar el desequilibrio del cónyuge requirente. Para justificar este procedimiento se coloca el acento en los criterios que describe el artículo 62 de la LMC que, en su mayoría, miran hacia la situación actual y futura del cónyuge beneficiario. Así ocurre con su situación patrimonial, su estado de salud y edad, la previsión, su calificación profesional, etc. Es decir, la cuantía de la compensación está determinada por la vida que viene, siendo el menoscabo económico el resultado de las condiciones previstas en el artículo 61 de la LMC. Esta forma de entender la compensación económica se desprende del pasado, el cual sólo ocupa una función determinante para la existencia del menoscabo, quedando entregada su cuantificación al futuro a partir de la idea de equilibrio económico.

Sin embargo, entender la institución de esta manera desatiende las reglas que la gobiernan, introduciendo una función que le es ajena. La compensación económica no busca el equilibrio patrimonial entre los cónyuges producida la ruptura, tampoco debe asignársele la función de intentar mantener o no alterar la situación económica o estándar de vida, sino que su marcado carácter indemnizatorio exige focalizar la mirada en el pasado de la relación conyugal.

\section{B. La mirada hacia el pasado}

El esfuerzo para cuantificar la compensación económica debe centrarse en observar el sacrificio operado por el cónyuge requirente durante la vida matrimonial. Uno debe partir de la idea de que el matrimonio constituye un proyecto de vida familiar que exige ventajas y sacrificios por ambos cónyuges. Un pacto destinado a un fin común y consentido para la construcción del bienestar familiar. Es usual, y Chile no es la excepción, que la mujer asuma una función protagónica en el hogar postergando su desarrollo individual. La crianza de los hijos y la organización o ejecución de las tareas del hogar quedan entregadas a la mujer. ${ }^{21}$ Estas tareas están justificadas por ese proyecto común matrimonial, quedando la mujer amparada en el estatuto protector matrimonial. De ahí la justificación y causa de la postergación de la mujer en el plano laboral remunerado, lo cual significa tranquilidad e impulso al desarrollo profesional del marido. Sin embargo, una vez que fracasa el proyecto matrimonial ocurre que las funciones que se asumieron

${ }^{20}$ Saura Alberdi (n. 1), pp. 53 y ss. Ahí se detiene la autora sobre la noción de desequilibrio económico, noción fundamental en la pensión compensatoria española.

${ }^{21}$ Ver datos del trabajo doméstico asumido por la mujer que ratifican esta aseveración en http://www. sernam.cl/cedocvi/basemujer/docs/CON(5)_20080708_172134.xls La información refleja la distribución de población inactiva dedicada al trabajo doméstico por regiones y sexo. Para constatar las tasas de trabajo doméstico por sexo y edad consultar http://www.sernam.cl/cedocvi/basemujer/docs/CON(5)_20080708_170338. xls Las estadísticas contienen una muestra entre los años 1996-2006. 
durante el matrimonio comienzan a trastabillar. Se instala una zozobra, inquietud y desazón en aquel cónyuge que observa que su trabajo doméstico ya no tiene razón de ser, dejándola en una situación de precariedad hacia el futuro. El fracaso del proyecto matrimonial excluye la causa de la función asumida durante el matrimonio por la mujer. Ahora se revela como un sacrificio la postergación de su desarrollo profesional, así como los beneficios que su actividad generó para el marido. Es esta circunstancia la que justifica indemnizar al cónyuge dicho sacrificio. La mirada debe, entonces, focalizarse en el pasado, en la magnitud del menoscabo económico padecido por el cónyuge requirente. La cuantía está determinada por la mensura del sacrificio que por el divorcio carece de causa que lo justifique. La "compensación” es el pago mensurable en dinero de la postergación del cónyuge requirente durante la vida conyugal.

Asumido el criterio indemnizatorio con una necesaria mirada al pasado, debe resolverse la forma en que operan los criterios previstos en el artículo 62 que, en su mayoría, como se dijo, colocan el acento en la situación al momento del divorcio y el futuro del cónyuge beneficiario.

Efectivamente algunos de dichos parámetros aluden a la situación actual o futura del cónyuge solicitante. También, es efectivo, que las circunstancias del precepto cumplen una doble función, orientada a auxiliar al artículo 61 en la determinación de la existencia del menoscabo, y para cuantificar la compensación. ${ }^{22}$ Ahora, me parece que la forma apropiada de utilizar dichos criterios, asumido el carácter indemnizatorio de la compensación, y superada la fase de acreditación del menoscabo económico, consiste en considerarlos para mensurar el sacrificio patrimonial del cónyuge solicitante. Cada criterio debe colocarse en perspectiva hacia el pasado, a fin de observar si concurre un mayor o menor menoscabo. Así, por ejemplo, si el cónyuge solicitante dedicó 15 años de su vida a las tareas del hogar y el cuidado de los hijos y se encuentra sin previsión, deberá concluirse que el menoscabo económico es significativo. No por la razón que se pretenda reconocerle una previsión hacia el futuro, sino porque su sacrificio significó la exclusión de un sistema previsional a su favor. Si se trata de un cónyuge de avanzada edad y un estado de salud frágil, el sacrificio debe valorarse con mayor entidad. Esta circunstancia está atada al pasado, a la convivencia efectiva de los cónyuges. Mal podría justificar la avanzada edad por sí misma una compensación económica si el matrimonio fue celebrado por personas de avanzada edad. ${ }^{23}$ Lo que ratifica el carácter indemnizatorio al vincular la avanzada edad y el estado de salud con lo que fue la relación conyugal. La ausencia de calificación profesional se explica por un desempeño intenso durante el matrimonio y, una vez más, la cuantía aumentará. En sentido inverso, puede ocurrir que el pasado en la relación conyugal excluya en forma íntegra la compensación, pues si bien el futuro se ve precario, el menoscabo es irrelevante para justificar la compensación. Esto ocurrirá en forma usual en matrimonios de escasa duración, lo cual puede asociarse a una situación económica estable del cónyuge solicitante. ${ }^{24}$ En

22 Turner (14), p. 485, ya citada.

${ }^{23}$ En este sentido, Turner (n. 14), p. 501.

${ }^{24}$ En este sentido, Corte de Apelaciones de Santiago, 27 de diciembre de 2006, No ingreso 6832-2006. Se trataba de un matrimonio sin hijos y la convivencia nupcial se prolongó no más de dos años, habiéndose 
consecuencia, si bien dichas circunstancias miran hacia el futuro, la forma en que deben operar está orientada a mensurar el menoscabo económico ya padecido por el cónyuge solicitante. ${ }^{25}$ En ningún caso se trata de reequilibrar patrimonios o prolongar el estándar de vida del cónyuge requirente. ${ }^{26} \mathrm{El}$ matrimonio se acabó, y con él todo el sistema protector que conlleva. El proyecto de vida se fracturó de manera irremediable, por eso toca hacer las cuentas mirando cuáles fueron los sacrificios que se hicieron; para esto, las circunstancias del artículo 62 y otras que puedan aplicarse serán fundamentales para calificar la entidad del sacrificio a indemnizar. La profesora Turner acierta al señalar que "la tarea cuantificadora está regida por la discrecionalidad judicial y la enumeración de circunstancias no implica en caso alguno que el juez esté sujeto a tablas o baremos para fijar su monto". ${ }^{27}$

Esta conclusión permite aclarar la función de las circunstancias del artículo 62 a partir de la calificación indemnizatoria de la compensación económica. Todavía es necesario avanzar sobre cómo deben entenderse en particular dichos criterios y cuál podría ser un modelo apropiado de cálculo de la compensación.

\section{LA CUANTÍA A PARTIR DE LOS CRITERIOS DEL ARTÍCULO 62}

La tarea más ardua, entre otras, que han enfrentado los jueces en aplicación de la LMC ha sido determinar la cuantía de la compensación económica. ${ }^{28}$ Verificada la existencia

dedicado la cónyuge solicitante a estudiar derecho y literatura en francés durante ese período. La Corte indicó "Que, en estas condiciones, teniendo en consideración que la compensación económica requiere la existencia de menoscabo económico para alguno de los cónyuges que sea consecuencia de no haber podido desarrollar una actividad remunerada o lucrativa durante el matrimonio, o de haberlo hecho en menor medida de lo que podía y quería, por haberse dedicado al cuidado de los hijos o a las labores propias del hogar común durante el lapso que las partes entienden duró la convivencia, pues aunque la cifran en dos años, ese sería el tiempo en que el marido trabajó en la cuarta región, y en todo caso, no se probó que ello le hubiere impedido desarrollar una actividad remunerada o lucrativa o, al menos, que hubiera tenido que hacerlo en menor medida -como dice la ley- de lo que eran sus posibilidades y su deseo".

${ }^{25}$ En un sentido contrario, Corte de Apelaciones de Concepción, N ${ }^{\circ}$ de ingreso 2370-2006, para la cual "Que si bien está acreditado con la prueba rendida que la señora Perelló durante la vida en común no pudo desempeñar con continuidad ni estabilidad una actividad remunerada por haberse dedicado al cuidado y crianza de sus hijos y a los continuos traslados de su marido, no resulta acreditado que se encuentre en una situación económica desmedrada por el término de su matrimonio". Y, agrega, "Que, en efecto, la demandante reconvencional está integrada al mercado laboral, con un patrimonio que resulta bastante para solventar cómodamente su vida, por lo que no aparece necesario compensar el menoscabo, si lo hubiere". Aquí la situación patrimonial del cónyuge requirente al momento del divorcio fue determinante para excluir la compensación, aún sí hubiere existido menoscabo económico. La circunstancia de la situación patrimonial operó como un correctivo excluyente de la compensación.

${ }^{26}$ Razón por la cual la doctrina francesa y española no siempre son ilustrativas para el análisis de nuestra legislación.

27 Turner (n. 14), p. 486.

${ }^{28}$ Es un fenómeno usual en el derecho comparado. Saura (n. 1), p. 167 sostiene "Se presenta como una labor más que complicada, la tendente a la delimitación y establecimiento, en cada caso, de la cantidad adecuada, en concepto de pensión”. Algunos intentos por abordar este problema en la doctrina española en Marfil, J.A., "Hacia un planteamiento racional de la pensión compensatoria, la tabulación”, Revista de Derecho 
del menoscabo económico generado por reunirse en el cónyuge demandante las condiciones previstas en el artículo 61 de la LMC, con el auxilio de los criterios específicos reseñados en el artículo 62, el juez se encuentra en situación de cuantificar el monto de la compensación a que será condenado el cónyuge deudor. El juez debe fijar un monto único, sin perjuicio de las modalidades o parcialidades a que estará sujeto el pago.

El estado actual de la cuestión en la doctrina nacional es más bien desalentador. La mayoría de los autores ha renunciado a proponer algún ejercicio para cuantificar la compensación o sólo se ha limitado a la descripción de los parámetros previstos en el artículo 62 de la LMC. En contraste, al menos, una autora ha realizado un análisis mayor de dichos parámetros. ${ }^{29}$ Por su parte, en la jurisprudencia, también existe una diferencia entre el procedimiento general en que se verifica una ausencia de argumentación y una notable excepción de la Corte de Apelaciones de Santiago.

\section{A. La cuantificación de la compensación económica en la doctrina}

Esta tarea ha sido denunciada como difícil, renunciando al intento de cuantificar la compensación, dejándolo en manos de la discreción judicial, la cual se asume como riesgosa. Para el profesor Corral, "la cuantía de la compensación económica debiera fijarse en función del perjuicio o menoscabo económico. Pero es difícil -por no decir imposible- que verdaderamente se puedan resarcir completamente todos los perjuicios patrimoniales que el cónyuge sufre por el desahucio unilateral de todo el estatuto protector del matrimonio, sobre todo porque se trata de beneficios eventuales o potenciales que no sabemos si habrían tenido lugar o se habrían extinguido por otra causa" 30 . Por esta razón el profesor Corral renuncia a una cuantificación homologada a aquella del daño de la responsabilidad civil, indicando que "se trata de una compensación paliativa que intenta en la medida de los posible cubrir el menoscabo económico más manifiesto, y según pautas de orientación que la misma ley se encarga de fijar, aunque sea a modo ilustrativo". 31

Para el profesor Tapia, "el propósito es únicamente compensarlo -al cónyuge beneficiario- por las "chances" que perdió de acceder a un trabajo, pero no es una suma que cubra todos los ingresos que habría recibido de ejercer una profesión, pues es imposible determinarlos con precisión y aún afirmar categóricamente que de no haber contraído matrimonio habría ejercido tal actividad”. Su propuesta está marcada por la diversidad de situaciones en que puede encontrarse el cónyuge demandante. Por eso afirma que

de Familia, $\mathrm{N}^{\circ} 6,1999$, p. 23, quien propone una tabla para la cuantificación asociada a la temporalidad de la convivencia.

${ }^{29}$ Turner (n. 14), pp. 486 y ss.; en un trabajo posterior, la misma autora se refiere al trabajo doméstico, Turner Saelzer, S., "La valoración del trabajo doméstico y su influencia en la compensación económica", en Estudios de Derecho Civil II. Jornadas nacionales de derecho civil, Olmué, 2006, Santiago, LexisNexis, 2007, pp. 211 y ss.

${ }^{30}$ Corral (n. 6), p. 28.

${ }^{31}$ Ibidem. 
"estos criterios ajustan la compensación económica a la diversa realidad que existe tras la ruptura y entrega herramientas para que los jueces puedan prudencialmente fijar una suma". 32

La profesora Domínguez Hidalgo al ocuparse de la evaluación señaló en su oportunidad "lógico es que siga en esto el destino evidente que tienen todos los tipos de perjuicios que no tienen un equivalente económico exacto $y$, por ende, donde toda idea de compensación por equivalente exacto se hace imposible como acontece con el lucro cesante en las personas o el daño moral". ${ }^{33}$ Por esto, corrigiendo una opinión sostenida por este autor en el sentido de utilizar las formas o criterios de avaluación del daño moral, la profesora Domínguez lo extiende a todos aquellos daños cuya avaluación exacta resulta imposible. Por eso expresa que correspondería asimilar el régimen de evaluación de la compensación económica a todos los perjuicios de compleja traducción económica. ${ }^{34}$ Y concluye entregando la evaluación a la "apreciación prudencial de los tribunales su monto", denunciando enseguida los problemas y peligros usuales en estos casos: "arbitrariedad en las decisiones, falta de uniformidad en las decisiones judiciales, falta de fundamentación en las decisiones, etc. En otras palabras, todos los problemas que la partida del daño moral experimenta en el presente pueden plantearse en la evolución futura de la compensación”. ${ }^{35}$ A pesar de este pesimismo manifiesto, la profesora Domínguez saluda que el legislador haya establecido criterios expresos y no taxativos para orientar la fijación de la cuantía.

El profesor Guerrero Becar también se mostró desalentado al expresar que "no existe igual avance en la fijación de un modelo o parámetro de cuantificación de la compensación, que queda al absoluto arbitrio de los sentenciadores. Los autores nacionales -continúa-, en general, han volcado su preocupación a definir la naturaleza jurídica de la institución y estudiar los criterios que el legislador indica al juez para fijarla, pero han preterido desarrollar y sobre todo especificar tales criterios en función de evitar que la cuantificación quede entregada en forma plena al sentenciador...el paso siguiente, de determinar la cuantía específica, es olvidado y ella queda entregada a la prudencia del juez que toma en consideración la situación del deudor sólo a efectos de fijarle formas de pago". ${ }^{36}$ Sin embargo, el propio Guerrero enseguida renuncia a dicha tarea que con tanto ahínco denunció al sostener que "no podemos dudar ser (sic) tarea difícil fijar la cuantía de la compensación económica, ni es nuestra intención establecer un modelo para su cuantificación" y sólo recuerda la necesidad de fundamentar las sentencias en conformidad al artículo 66 de la vapuleada Ley $\mathrm{N}^{\circ} 19.968$ sobre Tribunales de Familia y el Auto Acordado de la Excma. Corte Suprema de 1920 sobre forma de las sentencias.

En forma escueta, el profesor Domínguez Águila afirma que "a diferencia de una reparación de daños patrimoniales, la ley no determina al juez a fijar el monto de la

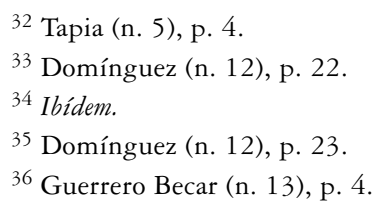


compensación en un equivalente a un daño causado. No es posible entonces usar los criterios de fijación del lucro cesante, pues en éste la indemnización debe ser equivalente a la ganancia perdida. Tampoco los propios de la obligación alimenticia, pues en ésta la pensión depende de las necesidades del alimentario y en función de la capacidad económica del alimentante". ${ }^{37}$

No existe, por consiguiente, un esfuerzo doctrinal a entregar pautas de evaluación más concretas, entregándose, una vez más, a la discrecionalidad judicial.

Sin embargo, es la profesora Susan Turner la que con mayor detenimiento se ha preocupado de las circunstancias explicitadas en el artículo 62 de la LMC. Luego de explicar la doble función "configurativa del menoscabo" y otra "cuantificadora del menoscabo", definir ciertas características transversales de los criterios y la relación entre ese precepto y aquel del artículo 61, procede al análisis particular de cada circunstancia. ${ }^{38}$ A esto se agrega el análisis de la valoración del trabajo doméstico como criterio esencial en la cuantía de la compensación. ${ }^{39}$ Por lo mismo no me parece útil realizar ese mismo ejercicio analítico a partir de las circunstancias previstas en la LMC. ${ }^{40}$ Sólo quisiera colocar el acento en los problemas de aplicación de las circunstancias por los tribunales y el modelo de cálculo utilizado que a continuación desarrollo.

\section{B. Las circunstancias del artículo 61 en la jurisprudencia y su relación con la cuantía de la compensación}

Dos tendencias marcadas muestra la jurisprudencia al momento de fijar la cuantía de la compensación. Por una parte, los jueces suelen en su gran mayoría desentenderse de cualquier esfuerzo explicativo para fijar el monto citando nada más los criterios del artículo 62, lo cual contrasta con excepcionales sentencias que denotan un esfuerzo argumentativo para justificar la cuantía.

1. La ausencia de fundamento en la aplicación de los criterios y su impacto en la cuantía

Los tribunales se limitan en sus sentencias a verificar la concurrencia de las condiciones de procedencia de la compensación, para luego replicar todas o algunas de las circunstancias del artículo 62 de la LMC. Esta es la forma usual de cuantificar la compensación económica. Sobre los factores críticos considerados por la jurisprudencia para asignar la compensación económica, destacan en primer lugar, la dedicación pasada a la familia de quien solicita compensación y la duración del matrimonio, en segundo lugar la calificación profesional del beneficiario, en tercer lugar la situación patrimonial del

\footnotetext{
${ }^{37}$ Domínguez Águila (n. 13), p. 91.

38 Turner (n. 14), pp. 492 y ss.

39 Turner (n. 29), pp. 216 y ss.

${ }^{40} \mathrm{Ibidem}$, aunque volveré sobre ello en la tercera parte a propósito de las pautas a proponer para llevar
} a cabo la cuantificación. 
demandado y en cuarto lugar las posibilidades de acceso al mercado laboral que tiene el solicitante de la compensación económica. Hay otros factores de menor impacto, edad y estado de salud del beneficiario. ${ }^{41}$

Para ejemplificar lo dicho expongo las siguientes sentencias.

En sentencia de la Corte de Apelaciones de Rancagua se cuantificó la compensación en cinco millones de pesos en razón de que la solicitante:

"por el lapso de tres años se dedicó al cuidado y crianza de sus hijos menores de modo preferente, por lo que deberá acogerse la demanda reconvencional...". 42

En un sentido similar, la Corte de Antofagasta se limita a reproducir los criterios indicados por el legislador en el artículo 61 de la LMC, aunque con ciertas insinuaciones valóricas. En el fallo se expresó:

"Que para determinar el monto de la compensación económica ha de considerarse la vida en común que tuvieron, la situación patrimonial del cónyuge demandante y la edad de la mujer, que ha quedado disminuida en su posibilidad de encontrar un trabajo dignamente remunerado acorde a su posición social frente a la situación jurídica que ella vivía antes de la publicación de la ley de familia, generando una injusticia que ella estaba imposibilitada de prever y mediante la cual el ordenamiento jurídico debió consignar un estadio intermedio para respetar el statu quo y las relaciones que el estado de derecho había mantenido por más de cien años”. 43 Se agrega, en la misma sentencia, que:

"para determinar el monto de la compensación económica, ha de considerarse la vida en común que tuvieron, la situación patrimonial del cónyuge demandante, especialmente el trabajo remunerado constante y que el padre tiene a su cargo el cuidado de los hijos por resolución judicial, desde que se produjo la separación, por lo tanto se estima que la suma de $\$ 1.000 .000$ (un millón de pesos), pagada en diez mensualidades de $\$ 100.000$ (cien mil pesos) representa la compensación solicitada". 44

Otro tanto ocurre con la sentencia de la Corte de Concepción:

"Que tomando en consideración, la duración del matrimonio, la vida en común, situación patrimonial de ambos, edad de los cónyuges, beneficios previsionales y

${ }^{41} \mathrm{El}$ análisis de la jurisprudencia no es exhaustivo, por razones de dificultad para acceder a las sentencias. Se realizó un catastro de sentencias en la base de datos de LexisNexis y en la página del Poder Judicial www.poderjudicial.cl Dicha búsqueda se ejecutó hasta diciembre de 2007 y se recopilaron un total de 286 sentencias entre los años 2005 y 2007.

42 Corte de Apelaciones de Rancagua, 26 de septiembre de 2006, No de ingreso Corte 785-2006.

43 Corte de Apelaciones de Antofagasta, 20 de noviembre de 2006, No ingreso Corte 1035-2006.

${ }^{44}$ Op. cit. 
de salud, posibilidades de acceso al mercado laboral y colaboración prestada a las actividades lucrativas del otro cónyuge, entre otros factores, la Corte estima del caso regular la compensación económica en una suma de dinero prudencial en la suma (sic) de $\$ 500.000$ (quinientos mil pesos), que deberán ser pagadas en el plazo de 24 meses en cuotas iguales". 45

En este caso se trataba de un matrimonio cuya convivencia se extendió por 22 años, naciendo 6 hijos del matrimonio, desempeñándose la mujer en trabajos ocasionales, las tareas del hogar, la crianza de los hijos y estudiando. ${ }^{46}$

De la lectura de estas sentencias y otras, uno puedo constatar que los jueces se centran en verificar las condiciones de procedencia de la compensación, dejando la cuantía en un margen amplio de discrecionalidad que se justifica reproduciendo algunos de los criterios indicados por el legislador en el artículo 62. No existe, por regla general, un método de cálculo asociado a la aplicación de las circunstancias.

\section{El esfuerzo excepcional: criterios y cálculo}

Ha sido la Corte de Apelaciones de Santiago donde encontramos la sentencia más relevante que denota un esfuerzo significativo para justificar la cuantía de la compensación económica otorgada. ${ }^{47}$ En el caso en cuestión, la compensación económica fue reclamada por vía reconvencional, habiéndose acreditado por la cónyuge requirente que se dedicó al cuidado de sus tres hijos y al hogar en común sin ejecutar actividad remunerada desde la época del matrimonio en el año 1966 hasta el cese efectivo de la convivencia ocurrida en el año 1990. Con posterioridad, a partir del año 1995, comenzó a trabajar como secretaria manteniendo su trabajo hasta la fecha del juicio de divorcio. Estos antecedentes llevaron a concluir a la Corte que era posible presumir el menoscabo económico.

Luego agrega la sentencia que:

“para determinar la real dimensión del menoscabo económico sufrido y la cuantía de la compensación, no basta con mirar hacia el pasado «buscando establecer la medida del empobrecimiento» sino que es menester examinar también otros aspectos que permiten evaluar la proyección o consecuencia de ese menoscabo en la vida futura del cónyuge solicitante. Es así como el legislador contempló, en el artículo 62 de la nueva Ley de Matrimonio Civil, una serie de criterios que el sentenciador habrá de aplicar...”. En seguida, la sentencia fija los siguientes parámetros destinados

${ }^{45}$ Corte de Apelaciones de Concepción, $\mathrm{N}^{\mathrm{o}}$ de ingreso Corte 161-2007.

${ }^{46}$ En el mismo sentido con cita de criterios sin un fundamento justificativo, Corte de Apelaciones de Concepción, $\mathrm{N}^{\circ}$ ingreso 217-2006, aunque en este caso la Corte rebaja la compensación invocando el criterio de la situación patrimonial del requirente no considerado por la sentencia del juzgado.

${ }^{47}$ Corte de Apelaciones de Santiago, 26 de enero de 2007, No ingreso 676-2006. No es casual que la sentencia haya sido redactada por la profesora de derecho civil Andrea Muñoz Sánchez en calidad de abogada integrante, la cual se ha especializado en derecho de familia. 
a orientar la cuantificación de la compensación, indicando en forma específica su relación con la situación de los cónyuges:

La duración del matrimonio: 40 años

Convivencia efectiva: 24 años

Edad y estado de salud de la mujer: 61 años de edad, actualmente sana, pero con un antecedente de cáncer mamario tratado, que le significa controles médicos semestrales para prevenir nuevas manifestaciones de la enfermedad.

Situación patrimonial del cónyuge demandante: la solicitante presta servicios a honorarios en el Hospital Clínico de la Universidad Católica, desempeñando labores de secretaria; que es propietaria de un departamento en el cual vive en la actualidad, no constando si mantiene deuda con el sistema financiero por este concepto.

Situación previsional: que no está afiliada a ningún sistema previsional que la habilite para obtener una jubilación y que en materia de salud, hasta la fecha ha sido carga del demandante principal en su plan de salud, situación que hacia el futuro dependerá de la voluntad del solicitante.

Ingresos por pensión alimenticia: a partir de la separación de hecho, el demandado reconvencional le ha entregado a la actora una pensión de alimentos de aproximadamente $\$ 400.000$ mensuales.

Régimen patrimonial del matrimonio: Que consta en autos que los cónyuges se separaron de bienes y liquidaron la sociedad conyugal de común acuerdo, conforme lo autoriza el artículo 1723 del Código Civil, por escritura pública de 20 de diciembre de 1982, adjudicándose cada cual, bienes por un valor cercano a los dos millones y medio de pesos de la época. ${ }^{48}$

Situación económica del cónyuge demandado: se trata de un médico cirujano de vasta trayectoria y reconocido prestigio, que se ha desempeñado ininterrumpidamente como ginecólogo por espacio de 40 años, salvo esporádicos viajes de perfeccionamiento al extranjero. Recibe en la actualidad una suma mensual aproximada de \$1.800.000; que paralelamente ha tenido oportunidad de ejercer con éxito su profesión en forma privada

${ }^{48}$ La sentencia es destacable al realizar la relación entre la compensación económica y el régimen económico del matrimonio, refiriéndose en forma expresa a los gananciales y adjudicaciones a favor de los cónyuges una vez efectuada la liquidación: “cuestión que, en ningún caso, priva a la solicitante del derecho a compensación económica, en la medida que concurran los requisitos legales para hacerlo. En efecto, mientras la compensación económica está destinada a reparar el menoscabo que se produjo en el patrimonio de uno de los cónyuges como consecuencia de haberse dedicado durante el matrimonio al cuidado de los hijos o del hogar común, en la medida que ello le impidió desarrollar una actividad remunerada, la liquidación de la sociedad conyugal es la forma ordinaria de poner término a la comunidad que se forma entre los cónyuges, al disolverse dicho régimen matrimonial, por cualquiera de las causas que contempla la ley. Lo anterior significa que los gananciales obtenidos al liquidar la sociedad conyugal tienen una causa jurídica distinta e independiente de los hechos que motivan la compensación económica y, en consecuencia, no cabe sustitución alguna entre ellos. Cosa distinta es que al determinarse la procedencia y cuantía de la compensación, se atienda, entre otros criterios, a la situación patrimonial de ambos cónyuges". 
a través de una sociedad. Era propietario de un departamento ubicado en Santiago, hasta marzo de 2004, por el cual percibía una renta de arrendamiento que entregaba a su cónyuge, hasta poco después de iniciado el presente juicio.

La aplicación de los criterios precedentes hicieron concluir al tribunal sobre la existencia del menoscabo, pero lo más notable lo constituye el considerando $11^{\circ}$ que explica la cuantía y que a continuación transcribo:

"11". Que para determinar la cuantía de la compensación se tomará como referente una suma similar a lo que en la actualidad percibe la solicitante mensualmente, esto es, de \$400.000, menos cotizaciones previsionales que para estos efectos estimaremos sólo en un $13 \%$, lo que arroja un monto de \$348.000. Lo anterior, por entender que si la actora puede generar ingresos por ese valor, en la actualidad, a los 61 años y sin ninguna capacitación especial, es perfectamente razonable suponer que habría estado en condiciones de producir, a lo menos, ese mismo ingreso, durante los 24 años de convivencia. Por otra parte, si ello hubiera sido así, la solicitante habría tenido oportunidad de cotizar en el sistema previsional, acumulando a esta fecha un capital sobre la base del cual se calcularía su pensión de vejez. En consecuencia, a lo anterior se agregará la cantidad que resulte de calcular el $13 \%$ de $\$ 400.000$ (tasa de cotización estimada) durante el período de 24 años. Se tiene presente, en todo caso, que el matrimonio estaba casado bajo el régimen de sociedad conyugal, por lo que el trabajo de la mujer habría dado lugar a un patrimonio reservado (artículo 150 del Código Civil), que podemos estimar debió colacionarse al haber social al momento de la liquidación de la sociedad conyugal, verificada en 1982, toda vez que la situación económica del matrimonio a esa fecha no habría ameritado, razonablemente, que la cónyuge hubiera renunciado a sus gananciales. Así las cosas, los cálculos anteriores dan el siguiente resultado:

a) Ganancias que podría haber generado la solicitante entre los años 1966 y 1982 (fecha en que se liquidó la sociedad conyugal) resultan de multiplicar \$348.000 por 192 meses: $\$ 66.816 .000$;

b) Liquidación de la sociedad conyugal en el año 1982, supone que dichas ganancias se dividen en mitades, correspondiéndole a cada cónyuge una suma de \$33.408.000;

c) Ingresos posteriores a 1982 y basta 1990, debieron quedar integramente en el patrimonio de la solicitante, al comenzar a regir la separación de bienes como régimen matrimonial, lo que significa \$348.000 por 96 meses: \$33.408.000; d) Cotización estimada de $13 \%$ sobre una remuneración de $\$ 400.000$, por espacio de 288 meses: \$14.976.000.

En consecuencia, los cálculos anteriores permiten estimar, prudencialmente, el monto de la compensación económica solicitada, en una suma de \$81.792.000. $12^{\circ}$. Que considerando que la solicitante es dueña del inmueble donde vive y no habiéndose becho constar que tenga alguna deuda con el sistema financiero que la obligue a pagar un dividendo mensual por esa propiedad, se deducirá prudencialmente del monto anterior, un $10 \%$, lo que arroja un monto final de \$73.612.800, que el demandado reconvencional deberá pagar a la demandante por concepto de compensación económica, más el interés corriente desde que la presente sentencia quede ejecutoriada, hasta la fecha de su pago efectivo". 
Esta sentencia constituye el intento más serio hasta ahora para justificar la cuantía de la compensación económica. No existe una discrecionalidad absoluta, ni tampoco el tribunal a partir de la regla de la sana crítica en materia procesal provee de una sentencia sin fundamento. Aquí el juez otorga una relevancia significativa a la mirada hacia el pasado, aunque como lo indica no en forma exclusiva. Es esa mirada lo que justifica la compensación y magnitud del menoscabo económico. Es cierto que este no debe considerarse el caso paradigmático para el cálculo de la compensación económica. El juez despliega un análisis sobre la situación del cónyuge requirente considerando las circunstancias enumeradas en el artículo 62, como un elemento de dirección y orientación del cálculo de la compensación.

La sentencia en cuestión aplica con rigor la calificación indemnizatoria con un marcado acento hacia el pasado, aunque morigerado con las circunstancias previstas en el artículo 62. Esta sentencia permite orientar cuál debería ser la forma de cuantificar la compensación económica por los jueces.

\section{Propuesta de CUANTIFICACiÓN DE LA COMPENSACiÓN ECONÓMICA}

La compensación económica busca realizar el pago del sacrificio de uno de los cónyuges que durante la vida conyugal bajo el amparo del sistema de protección matrimonial postergó su desarrollo personal, a consecuencia de lo cual el otro cónyuge recibió un beneficio. La mirada para determinar la existencia y cuantía del menoscabo económico debe fijarse hacia el pasado. El juez debe determinar cuál fue el sacrificio operado por el cónyuge requirente de compensación durante la vida conyugal. Este es el primer elemento y fundamental para el cálculo de la compensación. Se trata de valorizar, con las dificultades que conlleva, el trabajo efectuado sin remuneración por el demandante de compensación. A esto refiere la valoración del trabajo doméstico. De ahí la afirmación correcta de estimar que "la realización del trabajo doméstico durante el matrimonio es uno de los componentes básicos de la prestación posmatrimonial”. ${ }^{49}$ De esta manera, el trabajo doméstico constituye un presupuesto de procedencia, pero al mismo tiempo en un criterio muy importante para la valoración del menoscabo económico. ${ }^{50}$

Por otra parte, debe considerarse el costo alternativo del requirente para el cálculo. El valor de lo que hizo y aquello que dejó de hacer o hizo en menor medida otorga la base numérica para el cálculo de la compensación económica. La valoración del trabajo ejecutado varía según las tareas asumidas, la presencia, ausencia y cantidad de hijos, y la organización del hogar. En cierta medida el trabajo doméstico constituye un primer escalón para fijar la cuantía.

\footnotetext{
49 Turner (n. 29), p. 217.

${ }^{50}$ Op. cit., p. 219.
} 
La segunda operación debe estar orientada a valorar el costo alternativo. Es decir, aquello que sacrificó el requirente por dedicarse al hogar y al cuidado de los hijos. Este ítem varía según las características profesionales al iniciar la convivencia contrastándolas con las posibilidades de inserción laboral al momento del divorcio. Si al iniciar la convivencia la mujer era profesional, dejando de lado su trabajo o búsqueda del mismo deberá aumentarse la compensación, pues se verifica un mayor sacrificio al quedarse en la casa. En cambio, si carecía de formación universitaria y sus expectativas laborales eran bajas, no habrá un aumento en la valoración.

Para estimar en dinero me parece apropiado el criterio propuesto por la sentencia analizada. Es decir, deberá valorizarse el trabajo doméstico, que en general debiera acercarse a la remuneración que recibe una persona por esas tareas. Hoy, por ejemplo, el trabajo doméstico varía entre el salario mínimo hasta los $\$ 500.000$ pesos según los estratos sociales. A esto debe agregarse, como se dijo, el costo de oportunidad según las cualidades profesionales o aptitudes para el trabajo del cónyuge demandante. Si al momento de contraer matrimonio se trataba de una ingeniera con dos años de experiencia que renunció a su trabajo, habrá que considerar cuál sería su remuneración si hubiere continuado trabajando. Esa remuneración en la diferencia que arroje con la valoración del trabajo doméstico deberá agregarse. Así, por ejemplo, si la mujer hubiere recibido hace cinco años una remuneración de 600 mil pesos, siendo la valoración del trabajo doméstico de 250 mil pesos, deberá quedar la base de cálculo en 600 mil. En cambio, si el cónyuge requirente carecía de estudios, tenía 20 años y quedó embarazada, dedicándose al hogar, sólo deberá contemplarse como base de cálculo la valoración del trabajo doméstico.

Una vez fijada la base del cálculo deberá multiplicarse por los años durante los cuales se efectuaron las tareas causantes del menoscabo económico. Luego, determinada esta cifra, procede realizar una deducción del $13 \%$ equivalente a la cotización obligatoria por concepto de jubilación. La suma que arroje constituye en su integridad compensación, pues habría sido el ahorro previsional del requirente. Claro, este porcentaje podrá pagarse con el traspaso de fondos de capitalización obligatoria hasta el límite del 50\% existente, si existieren, del cónyuge demandado, en conformidad al artículo 80 de la Ley 20.255, con independencia del régimen patrimonial entre los cónyuges.

A continuación, debe considerarse el régimen económico del matrimonio. Si están casados bajo el régimen de sociedad conyugal habrá que determinar si el cónyuge demandante habría o no renunciado a los gananciales, pues el cálculo de sus ingresos constituiría patrimonio reservado. ${ }^{51}$ En las hipótesis de separación de bienes y participación de gananciales, el régimen patrimonial no sería relevante, salvo en cuanto se considere la situación patrimonial.

Estos cálculos pueden padecer variaciones durante el período de tiempo a aplicarse. Ya sea porque hubo cambios en el régimen económico, que el requirente trabajó a tiempo parcial o por períodos discontinuos, etc.

\footnotetext{
${ }^{51}$ En este sentido la sentencia citada y analizada supra C.2.
} 
Una vez fijada dicha cuantía corresponde aplicar las circunstancias correctoras del artículo 62 que deberán ponderarse por el tribunal respectivo. Estos criterios podrán significar un aumento o una disminución de la compensación, debiendo relacionarse unos con otros, en la medida que fueren aplicables. Todos ellos, sin excepción, deben considerarse para mensurar la intensidad del menoscabo y sacrificio del cónyuge requirente durante el período que justifica la procedencia de la compensación. En esta fase la prudencia judicial tendrá un papel protagónico e insoslayable. Ya se sabe que no se trata de una lista cerrada, pudiendo el tribunal considerar otros factores no previstos en la ley.

A lo anterior debe sumarse una publicidad significativa de los casos en que se cuantifique la compensación económica. Las Cortes debieran ocuparse de proveer a los jueces de familia de las sentencias en que se otorgue compensación, a fin de ir avanzando en la necesaria equiparación de montos en casos similares o análogos. Esto requiere un esfuerzo de argumentación de los tribunales no sólo para determinar la existencia del menoscabo, sino también en lo relativo a la cuantía.

Es cierto que la inmensidad de la práctica revela la imposibilidad de crear un procedimiento exacto de cálculo. Un cierto pragmatismo y discrecionalidad permitirán morigerar los excesos a que pueda conducir una simple multiplicación aritmética de la base de cálculo. Pero a partir de estas pautas se podrá realizar el objetivo primordial de la compensación sin que ahora la jurisprudencia sea una fuente de desigualdad.

Tampoco se pretende un procedimiento exhaustivo, sino más bien indiciario, que permita a los jueces escapar a la desigualdad en el establecimiento de la compensación económica, siendo fiel a su calificación jurídica.

\section{BIBLIOGRAFÍA}

AA.VV., Daños en el derecho de familia, coordinador José Ramón de Verda y Beamonte, RDP Monografías, Navarra, Thomson-Aranzadi, 2006.

AA.VV., Dossier Pratiques Francis Lefebure. Réforme du divorce. Loi du 26 mai 2004, procédures, conséquences patrimoniales et fiscales, Levallois, Francis Lefebvre, 2004.

Bénabent, A., La réforme du divorce article par article, Paris, Defrénois, 2004.

Barrientos Grandón, J., "La compensación económica como "derecho" de uno de los cónyuges y "obligación” correlativa del otro. De sus caracteres", $R c h D P, 2007, \mathrm{~N}^{\circ} 9$.

Barrientos Grandón, J. y Novales Alquézar, A., Nuevo Derecho Matrimonial Chileno, Santiago, LexisNexis, 2004.

Carbonnier, J., Droit Civil. Quadrige. Manuels, Paris, Puf, vol. I, 2004.

Corral Talciani, H., "La compensación económica en el divorcio y la nulidad matrimonial", en Revista Chilena de Derecho, v. 34, No 1 .

Domínguez Águila, R., "La compensación económica en la nueva legislación de matrimonio civil”, en Actualidad Jurídica, vol. 15, 2007.

Domínguez Hidalgo, C., "Compensación económica en la nueva ley de matrimonio civil", charla efectuada el 13 de octubre de 2005, en Revista del Abogado, Serie conferencias, 2005.

Gómez de la Torre, M., "Compensación económica en la nueva ley de matrimonio civil", (Folleto Colegio de Abogados de Chile), Colegio de Abogados, Santiago, 2005. 
Guerrero Becar, J. L., "La compensación económica en la ley de matrimonio civil. Análisis jurisprudencial y sobre la necesidad de revisar los supuestos de procedencia”, en Revista de Derecho, Pontificia Universidad Católica de Valparaíso, vol. XXVII, 2006.

Herane Vives, F., "Reparación por incumplimiento de los deberes matrimoniales", en Estudios de Derecho Civil II, Jornadas nacionales de derecho civil, Olmué, 2006, Santiago, LexisNexis, 2007, coordinadores H. Corral T. y M. S. Rodríguez Pinto.

Lalana del Castillo, C., La pensión por desequilibrio en caso de separación o divorcio, Barcelona, Bosch, 1993.

Malaurie, Ph. y Aynés, L., La Famille, París, Defrénois, 2006.

MarfiL, J.A., "Hacia un planteamiento racional de la pensión compensatoria, la tabulación", Revista de Derecho de Familia, Nº, 1999.

Massip, J., Le nouveau droit du divorce, Paris, Defrénois, 2005.

Novales Alquézar, M. de A., "Hacia una teoría general de la responsabilidad civil en el derecho de familia", en Revista del Notariado, No 60, 2006.

Pizarro Wilson, C., "La compensación económica en la nueva ley de matrimonio civil chilena", en $R C h D P, \mathrm{~N}^{\circ} 3,2004$.

Saura Alberdi, B., La pensión compensatoria; criterios delimitadores de su importe y extensión, Valencia, Tirant, 2004.

Segura Riveiro, F., "La compensación económica al cónyuge más débil”, en Revista de Derecho, Universidad de Concepción, No 214, julio-diciembre 2003.

TAPIa Rodríguez, M., "Constitucionalización del derecho de familia(s), el caso chileno: las retóricas declaraciones constitucionales frente a la lenta evolución social, en $R C h D P, \mathrm{~N}^{\circ}$ 8, 2007.

TAPia Rodríguez, M., "Sobre la función y criterios de determinación de la compensación económica matrimonial”, en Semana Jurídica, enero 2007.

Vidal Olivares, A., "La compensación por menoscabo económico en la Ley de Matrimonio Civil", en Vidal Olivares, A. (coordinador), El nuevo derecho chileno del matrimonio (Ley $N^{\circ} 19.947$ de 2004), Jurídica, Santiago, 2006.

Turner Saelzer, S., Las prestaciones económicas entre cónyuges divorciados en la nueva ley de matrimonio civil", en Revista de Derecho, Universidad Austral de Chile, vol. 16, 2004.

Turner Saelzer, S., "Las circunstancias del artículo 62 de la nueva ley de matrimonio civil: naturaleza y función”, en Estudios de Derecho Civil, Jornadas de derecho civil, Valdivia, coordinadores Juan Andrés Varas Braun y Susan Turner Saelzer, LexisNexis, Santiago, 2005.

Turner Saelzer, S., "La compensación económica en la nueva ley de matrimonio civil: tres cuestiones dogmáticas", en Revista Chilena de Derecho, vol. 32, No 3, 2005.

Turner Saelzer, S., "La valoración del trabajo doméstico y su influencia en la compensación económica”, en Estudios de Derecho Civil II. Jornadas nacionales de derecho civil, Olmué, 2006, Santiago, LexisNexis, 2007.

Veloso Valenzuela, P., "Algunas reflexiones sobre la compensación económica", en Actualidad Jurídica, $\mathrm{N}^{\circ} 13,2006$. 